\title{
Mounting Toll of Coronavirus Cases Raises Concerns for Mental Health Professionals
}

\author{
Aisha Noorullah \\ Bahria University, Karachi, Pakistan
}

The unfamiliar, new fangled and perilous coronavirus [COVID-19] illness commenced in China's Wuhan city, which has engulfed almost half of the world, and declared as pandemic by WHO on March 11, 2019. 'At the time of writing, the religious festival, Eid-ulAzha is around the corner, if appropriate protective measures will not be practiced then a further spike in COVID-19 cases can occur.

In the global population ranking, Pakistan occupies the fifth position. ${ }^{2}$ Mental health has been a gravely neglected area in Pakistan. A frequently quoted statistics of 400 well trained psychiatrists in our country indicating approximately only one psychiatrist is available perhalf million people. ${ }^{3}$

In this pandemic situation, the mental health challenges exist in all regions of the world; but more in a developing country like Pakistan. As there is dearth of research into the area pertinentto COVID-19 and psychological issues, so general measures to improve mental health should bethe part of the bio-psycho-social multidisciplinary plan.

Acutely ill patients, during the hospitalisation period, may suffer from depressive and anxiety symptoms; for which mental health professionals should be taken on board including psychologist, psychiatrist or counsellors for non-pharmacological interventions. However, a severe case which may need medications is tricky; as being a new situation, no evidence is available from randomised controlled trial to be applicableto patients in this population. Quarantine also has negative psychological effects. ${ }^{4}$ People who are kept in seclusion, as part of being close contacts of diagnosed cases, also require psychological support due to isolations and inconclusiveness. Cohort of people already diagnosed with psychiatric disorders can have relapses as they might not be able to have routine followups as the OPDs are occuring in an erratic manner. Hence, non-compliance of medications due to multitude of factors should be approached through online sessions. The fatality rate is arising substantially so the survivors of the deceased will also require interventions to be watched for normal bereavement versus pathological grief.

Correspondence to: Dr. Aisha Noorullah, Bahria University, 13, National Stadium Road, Karachi, Pakistan E-mail: aishasid01@gmail.com

Received: March 19, 2020; Revised: June 13, 2020;

Accepted: June 13, 2020

DOI: https://doi.org/10.29271/jcpsp.2020.07.677
Survivor guilt can be found among beloved ones in the long run. An overall atmosphere of threat and ambiguity can be calmed down to some extent by responsible media reporting, true depiction of confirmed cases, new cases, and death rates on as required basis. Taking care of emotional wellbeing of health professionals, who are more endangered, is also pivotal to the whole process. Professionals' psychological needs must also beaddressed.

Non-pharmacological / psychosocial measures, which can be helpful, include psycho-education, supportive counselling, crisis intervention, CBT etc. Overall approach should be to promote understanding and adoption to the psychosocial effects of COVID-19 illness. For all these interventions, telepsychiatry/ telepsychology option [online sessions] should be considered to avoid face-to-face encounters. ${ }^{5}$

Mental health professionals have a vital role to play in creating an atmosphere of support and dignity, fortified with threads of hope, to reduce stigmatisation, alienation, and discrimination. The art of medicine and love of humanity go hand-in-hand. This rapidly evolving crisis legitimises the implementation of mental health services as a fundamental step. The lessons/outcomes learnt from these interventions should be reported by scientific researches to help us in preparing for any subsequent emergency situation.

\section{REFERENCES}

1. Coronavirus disease (COVID-19), outbreak. World Health Organization. http://www.who.int/westernpacific/emergenci es/covid-19.

2. Pakistan Population Worldometer. http://www.worldo meters.info/world-population/pakistan-population [Accessed on 19-04-2020].

3. Jooma R, Minhas FA, Saxena S. WHO-AIMS report on mental health system in Pakistan. World Heal. Organ. http:// www.who.int/mental_health/pakistan_who_aims_report. pdf. 2009.

4. Brooks SK, Webster RK, Smith LE, Woodland L, Wessely S, Greenberg N, et al. The psychological impact of quarantine and how to reduce it: Rapid review of the evidence. Lancet 2020; 395(10227):912-20.

5. O'Keefe M, White K, Jennings JA. Asynchronous telepsychiatry: A systematic review. J Telemed Telecare 2019; $1357633 \times 19867189$. 